\title{
SULFUR AND SELENIUM CONTAINING COMPOUNDS OF CHLOROPHYLL A DERIVATIVE
}

\section{Pogorilyy, E. Evdokimova, M. Khovrenkov, A. Mironov and M. Grin}

Institute of Fine Chemical Technologies, Federal State Budget Educational Institution of Higher Education «MIREA - Russian Technological University, 119571, Russia, Moscow, Prospect Vernadsky, 86.

DOI: 10.19163/MedChemRussia2021-2021-308

E-mail:pogorilviktor@gmail.com

Chlorins and bacteriochlorins are of limited use as PSs due to their high hydrophobicity, relatively low stability and moderate selectivity of accumulation in tumor cells. This dictates the need to create new, more stable derivatives of chlorins and bacteriochlorins with increased tendency to malignant neoplasms [1].

The introduction of exocyclic sulfur or selenium atoms into the structure of photosensitizers of the chlorine series was realized for the first time [2].

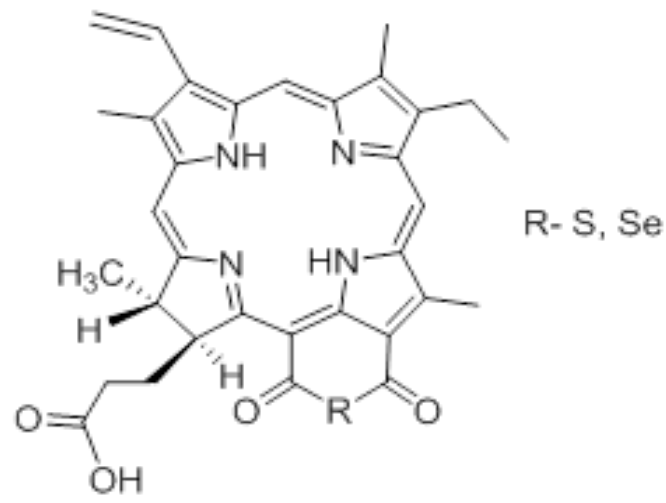

This made it possible to change the chemical and photophysical properties of pigments. Presumably, the increase in photoinduced activity as a result of this modification may be associated with a prooxidant effect on tumor cells [3]. Sulfur-containing and selenium-containing compounds can inhibit glutathionedependent enzymes, which leads to a weakening of the antioxidant system of tumor cells and an increase in their vulnerability to oxidative stress.

This work was carried out with the financial support of the Russian Foundation for Basic Research (№ 20-33-90289)

\section{References}

[1] A. Mironov, M. Grin, and et all, Journal of Medicinal Chemistry. 2017, 60(24), 10220-10230.

[2] V. Pogorilyy, M. Grin, and et all, Dyes and Pigments. 2021, 184, 108858.

[3] S. Singh, A. Khan, and et all, Journal of Experimental Therapeutics and Oncology. 2012, 9(4), 303-316. 